\title{
Preparation and Some Properties of Nanostructural Rare Earth Nitrides by Using the Reaction of Hydrides with Ammonia
}

\author{
Hayao Imamura*, Masahiro Kawasoe, Kyouya Imayoshi, Yoshihisa Sakata \\ Graduate School of Science and Engineering, Yamaguchi University \\ 2-16-1 Tokiwadai, Ube 755-8611, Japan \\ *hi-khm@yamaguchi-u.ac.jp
}

\begin{abstract}
By the use of the thermal decomposition of rare earth (RE) amides to nitrides, the preparation of nanostructural $R E$ nitrides (CeN, PrN, NdN, SmN, GdN, TbN, DyN, HoN and ErN) was extensively studied in search of optimal conditions. In this method, the preparation of amides as an effective precursor for the nitrides was similarly of importance; the amide was here prepared by high-pressure reactions of $R E$ hydrides with ammonia in an autoclave or reactive ball milling of the RE hydrides and ammonia. CeN, PrN, NdN and SmN were successfully prepared by the thermal decomposition of the RE amides or amide-like compounds formed by the reaction of the dihydrides with ammonia, whereas GdN, TbN, DyN, HoN and ErN were not obtained in this way. The dihydrides of gadolinium, terbium, dysprosium, holmium and erbium were generally too stable to react with ammonia to form the amides compared to those of cerium, praseodymium, neodymium and samarium. In the preparation of $\mathrm{CeN}, \operatorname{PrN}$ and $\mathrm{SmN}$, the amide precursors obtained by the autoclave reaction of the dihydrides with ammonia yielded nanostructural nitrides with higher surface areas (3.9-5.9 $\left.\mathrm{m}^{2} / \mathrm{g}\right)$, compared to those obtained by the reactive ball milling method.
\end{abstract}

Keywords: Rare earth, Amide, Nitride, Hydride, Ammonia, Ball Milling.

(C) Copyright 2015 Authors - This is an Open Access article published under the Creative Commons Attribution License terms (http://creativecommons.org/licenses/by/3.0). Unrestricted use, distribution, and reproduction in any medium are permitted, provided the original work is properly cited.

\section{Introduction}

There has been a growing interest in science and application of rare earth (RE) materials [1-3]. We have studied catalytic properties of a variety of RE compounds [4-8]. It has been recently found that RE nitrides are very active as a catalyst; thus europium and ytterbium nitride
(EuN and $\mathrm{YbN}$ ) obtained by the thermal decomposition of their amides show catalytic activity for the partial hydrogenation of benzene to cyclohexene $[9,10]$ and the selective dimerization of olefin [11]. Europium amide $\left(\mathrm{Eu}\left(\mathrm{NH}_{2}\right)_{2}\right)$ and ytterbium amide $\left(\mathrm{Yb}\left(\mathrm{NH}_{2}\right)_{2}\right.$ and $\left.\mathrm{Yb}\left(\mathrm{NH}_{2}\right)_{3}\right)$ prepared by taking advantage of the solubility of $\mathrm{Eu}$ and $\mathrm{Yb}$ metals in liquid ammonia are effective precursors for the formation of $\mathrm{EuN}$ and $\mathrm{YbN}$, respectively. The thermal decomposition of the europium and ytterbium amides thus obtained leads to active nanocrystalline EuN and $\mathrm{YbN}$ with high surface areas of $49-107$ and $123-146 \mathrm{~m}^{2} / \mathrm{g}$, respectively [10, 12, 13]. Thus the use of solubility of $\mathrm{Eu}$ and $\mathrm{Yb}$ in liquid ammonia provides a useful method for obtaining the active nanostructural nitrides.

Other RE metals than $\mathrm{Eu}$ and $\mathrm{Yb}$ exhibit poor solubility toward liquid ammonia, and hence similar procedures cannot be applied to the preparation of nitrides. There have been studies reported on many processes for the preparation of nitrides $[14,15]$, but none is fully satisfactory for catalysts. The direct reaction of RE metals with ammonia or nitrogen at elevated temperatures is undesirable for the preparation of stoichiometric nitrides [16].

Our investigation has been directed to the preparation of nanostructural RE nitrides with high surface areas. In view of the fact that the pyrolysis of the $\mathrm{Eu}$ amide and $\mathrm{Yb}$ amide was effective for the formation of nanostructural nitrides, in this study we undertook to use amides as a precursor of nitrides to synthesize nanostructural CeN, PrN, NdN, SmN, GdN, TbN, DyN, HoN and ErN.

$\mathrm{RE}$ hydride $+\mathrm{NH}_{3} \rightarrow \mathrm{RE}$ amide - (pyrolysis) $\rightarrow$ nanostructural RE nitride 
Therefore, by the use of the reaction of metal hydrides with ammonia to prepare amides as a precursor [17, 18], interest has centred on the preparation conditions and the influence of differences in preparation methods on the properties of the nitrides formed. This research has been reported in preliminary form [19]. The preparation of RE amides is here investigated by two methods; one was reactive ball milling under an ammonia atmosphere and the other was high-pressure reactions in an autoclave at 473-573 $\mathrm{K}$.

\section{Experimental}

\subsection{Materials}

RE metals (99.9\%; Ce, Pr, Nd, Sm, Gd, Tb, Dy, Ho and Er) were purchased from the Santoku Co. and used in powder form by filing. Ammonia gas (Iwatani Ind. Ltd.) was purified through a calcium oxide column and subsequently through a sodium hydroxide column.

\subsection{Procedures of sample preparation}

To prepare the RE hydrides, the reaction of the RE metals with hydrogen was carried out with a glass apparatus provided with a high vacuum system (ca. $2.7 \mathrm{x}$ $10^{-2} \mathrm{~Pa}$ ). Prior to the reaction, $\mathrm{Ce}, \mathrm{Pr}, \mathrm{Nd}$ or Sm powders were subjected to evacuation at $473 \mathrm{~K}$ for $2 \mathrm{~h}$, then the hydrogenation of the metals was carried out at room temperature by introducing hydrogen gas of $0.066 \mathrm{MPa}$ into a reactor with a fixed volume. Gd, Tb, Dy, Ho or Er powders were similarly evacuated at $623 \mathrm{~K}$ for $2 \mathrm{~h}$, followed by the hydrogenation at $473 \mathrm{~K}$. In all the metals used the amounts of absorbed hydrogen were determined by changes in pressures to become $\mathrm{RE}$ dihydrides.

The reaction of the dihydrides with ammonia was subsequently carried out with two methods. One was reactive ball milling (Fritsch Ltd.: P-6) under an ammonia atmosphere and the other was high-pressure reactions (12-14 $\mathrm{MPa})$ in an autoclave at 473-573 $\mathrm{K}$ for $48 \mathrm{~h}$. In a typical preparation of cerium amide by ball milling [19], cerium dihydride $(0.25 \mathrm{~g})$ was placed in a grinding bowl (made of zirconia; volume of $45 \mathrm{~cm}^{3}$ ), followed by introduction of $0.3 \mathrm{MPa}$ ammonia. The mixtures were subjected to ball milling with zirconia balls (diameter: $3 \mathrm{~mm}, 55 \mathrm{~g}$ ) for $0.25-20 \mathrm{~h}$, operated at $650 \mathrm{rpm}$. Ball milling of other dihydrides and ammonia was similarly carried out to yield the RE amides.
To obtain the RE nitrides, the amides thus prepared decomposed under evacuation in the temperature range $300-1073 \mathrm{~K}$.

\subsection{Characterization}

X-ray diffraction (XRD) analyses of the samples obtained were conducted with a Rigaku X-ray diffractometer (RINT 2200) using $\mathrm{Cu}-\mathrm{K}_{\alpha}$ radiation. Thermal desorption spectrum (TDS) measurements were made in vacuo at a heating rate of $3 \mathrm{Kmin}^{-1}$ by continuously monitoring desorbed gases via quadrupolar mass spectrometer (Canon ANELVA Co.: M101QA-TDF). Surface areas were measured with a Shimadzu TriStar 3000. All procedures of the RE samples obtained here were carried out without exposure to air.

\section{Results and Discussion}

\subsection{Preparation of $R E$ amides or amide-like compounds by the reactions of $\mathrm{RE}$ dihydrides with ammonia}

First the preparation of RE hydrides by the direct reaction of the RE metals with hydrogen gas was carried out with measuring the amounts of absorbed hydrogen [20]. The RE metals used reacted normally with hydrogen to form the dihydrides. Upon increasing the hydrogen pressures, the dihydrides additionally absorbed hydrogen until a composition near trihydrides was reached. The RE hydrides with the composition of $\mathrm{CeH}_{2.01}, \mathrm{PrH}_{2.01}, \mathrm{NdH}_{2.04}, \mathrm{SmH}_{2.02}, \mathrm{GdH}_{1.94}, \mathrm{TbH}_{1.99}, \mathrm{DyH}_{2.00}$, $\mathrm{HoH}_{1.71}$ and $\mathrm{ErH}_{1.84}$ were successfully prepared for use in this study, and the formation of all the dihydrides with a fluorite type structure was confirmed by XRD [20,21].

\subsubsection{Reactive ball milling of $\mathrm{RE}$ dihydrides and ammonia}

The RE dihydrides thus prepared were subsequently subjected to reactive ball milling under an atmosphere of $\mathrm{NH}_{3}$ for the reaction of the hydrides with ammonia; the hydride samples were placed in a grinding bowl made of zirconia, followed by introduction of ammonia gas at a pressure of $0.3 \mathrm{MPa}$. The mixtures were subjected to high-energy ball milling for $0.25-20 \mathrm{~h}$. The dihydrides of cerium, praseodymium, neodymium and samarium readily reacted with ammonia upon ball milling. According to time courses of changes in XRD, the diffraction peaks corresponding to the dihydrides were considerably broadened and gradually diminished with 
milling times, due to a rapid progress of the nanocrystallization and the following reactions with ammonia. The results on the cerium dihydride were shown in Figs. 1a-c as a typical example [19]. The cerium dihydride immediately reacted with ammonia upon ball milling, and the cerium samples during ball milling varied from initially black to mint green at the end. After ball milling for $7 \mathrm{~h}$, the XRD peaks of the dihydrides were hardly observed. However, there were no additional diffraction peaks which suggested new phases or products resulting from reactions of the cerium dihydride with ammonia; thus, no diffraction peaks assigned to the amide were observed. Although cerium amide was most likely formed upon reactions of the cerium dihydride with ammonia, regrettably, the formation of the cerium amide was not confirmed by XRD, probably due to a nanostructured or amorphous state. In reactive ball milling of the hydrides and ammonia, the dihydrides of praseodymium, neodymium and samarium showed behavior similar to the cerium dihydride as shown in Table 1, whereas the dihydrides of gadolinium, terbium, dysprosium, holmium and erbium hardly reacted with ammonia under the same milling conditions. The hydride phase of gadolinium, terbium, dysprosium, holmium and erbium remained unchanged during ball milling as shown in XRD results for dysprosium (Fig. 2) as an example. This is probably due to that the dihydrides of gadolinium, terbium, dysprosium, holmium and erbium are thermodynamically too stable to react with ammonia to form the amides compared to those of cerium, praseodymium, neodymium and samarium. The differences in the reactivity of RE hydrides thus observed are almost consistent with the order of hydride stability evaluated by the free energy of formation of the RE dihydride [20].

The samples obtained after ball milling of the dihydrides of cerium, praseodymium, neodymium or samarium with ammonia were found to be converted into the nitride when subjected to thermal treatment at around $873 \mathrm{~K}$ as described in the next section. This indicates that the reaction products by ball milling of $\mathrm{RE}$ dihydride (RE: $\mathrm{Ce}, \mathrm{Pr}, \mathrm{Nd}$ or $\mathrm{Sm}$ ) $/ \mathrm{NH}_{3}$ are certainly $\mathrm{RE}$ amides or amide-like compounds, which thermally decompose to the nitrides as described later in XRD and TDS results. Upon ball milling of the dihydrides of cerium, praseodymium, neodymium or samarium under an atmosphere of $\mathrm{NH}_{3}$, thus these hydrides readily reacted with ammonia, resulting in the formation of the $\mathrm{RE}$ amides as shown in eq. (1).

$\mathrm{RE}\left(\mathrm{Ce}, \mathrm{Pr}, \mathrm{Nd}\right.$ or Sm)dihydride $+\mathrm{NH}_{3}-($ ball milling $) \rightarrow \mathrm{RE}$ amide

Table 1. Crystal phases observed for samples after ball milling and pyrolysis.

\begin{tabular}{|l|l|l|l|l|l|l|l|l|l|}
\hline & \multicolumn{9}{|l|}{ Phase of rare earth samples } \\
\cline { 2 - 10 } & Ce & Pr & Nd & Sm & Gd & Tb & Dy & Ho & Er \\
\hline After ball milling & -a) & -a) & -a) & -a) & hydride & hydride & hydride & hydride & hydride \\
\hline After pyrolysis & nitride & nitride & nitride & nitride & hydride & hydride & hydride & hydride & hydride \\
\hline
\end{tabular}

a) amorphous

\subsubsection{High-pressure reactions of RE dihydrides with ammonia in an autoclave}

For the dihydrides of cerium, praseodymium and samarium which showed higher reactivity than those of gadolinium, terbium, dysprosium, holmium and erbium, the high-pressure reaction of the RE dihydrides with ammonia in an autoclave at elevated temperatures was further undertaken. In a $50 \mathrm{~cm}^{3}$ autoclave were placed the RE dihydrides under an atmosphere of dry nitrogen. The reactor was briefly evacuated, cooled by a dry ice/methanol bath, and then, about $4.4 \times 10^{-3} \mathrm{~m}^{3}$ of purified ammonia gas was liquefied. The reaction mixtures were subsequently stirred and the autoclave reaction was carried out under $12-14 \mathrm{MPa}$ at $473-573 \mathrm{~K}$ for $48 \mathrm{~h}$. Since the rise of reaction temperature induced the instability of RE hydride, resulting in acceleration of the reaction of hydride with ammonia, the reaction temperature of $573 \mathrm{~K}$ was more efficient than that of 473 $\mathrm{K}$. The reaction products of cerium dihydride $/ \mathrm{NH}_{3}$ at $573 \mathrm{~K}$ for $48 \mathrm{~h}$ were obtained as dark brown fine powders and the XRD results were shown in Fig. 1d, in comparison with the results on the products obtained by ball milling. There were no diffraction peaks arising from products or new phases in XRD, being similar to the results for the ball milling method as shown in Figs. $1 \mathrm{~b}$ and c. XRD of the reaction products for praseodymium and samarium were similar to that for cerium. 


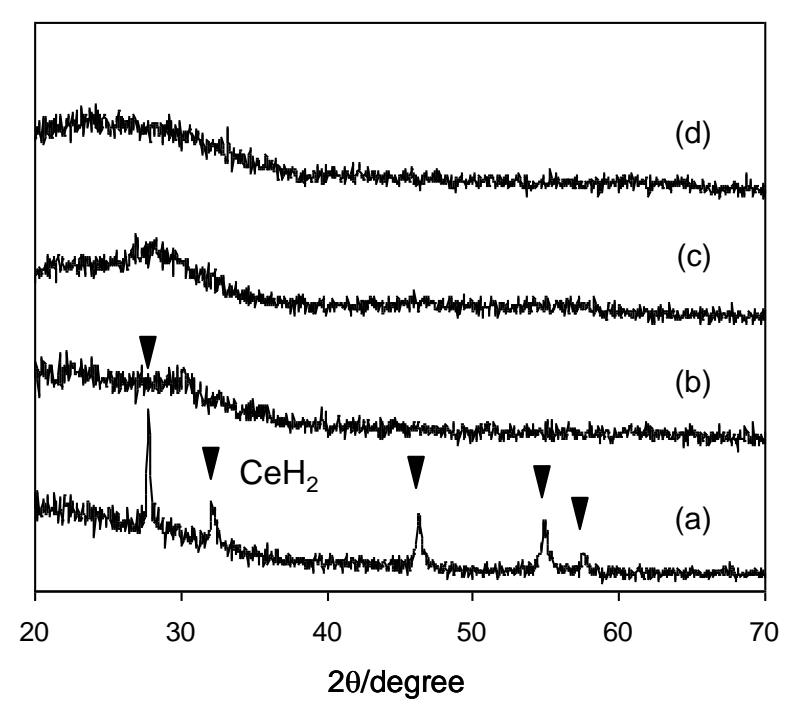

Figure 1. XRD results of the reaction products of cerium dihydride/ $\mathrm{NH}_{3}$.

(a) cerium dihydride as a starting material, (b) after ball milling for $3 \mathrm{~h}$, (c) after ball milling for $7 \mathrm{~h}$ and (d) after the autoclave reaction at $573 \mathrm{~K}$ for $48 \mathrm{~h}$.

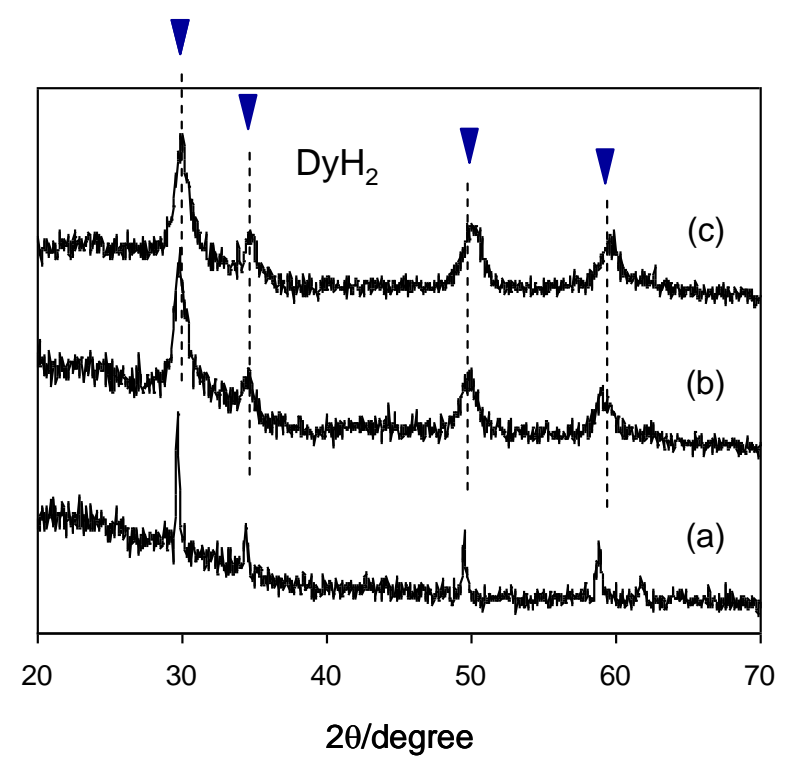

Figure 2. XRD changes with ball milling of dysprosium dihydride/ $\mathrm{NH}_{3}$.

(a) dysprosium dihydride as a starting material, (b) after ball milling for $5 \mathrm{~h}$ and (c) after ball milling for $7 \mathrm{~h}$.

\subsection{Thermal decomposition of reaction products of $\mathrm{RE}$ dihydride/ $\mathrm{NH}_{3}$ to nitrides}

To obtain the RE nitrides, the reaction products of RE dihydride $/ \mathrm{NH}_{3}$ thus obtained thermally decomposed under evacuation in the temperature range 300-1073 K. The thermal decomposition processes were followed by taking XRD measurements as a function of evacuation temperatures. As shown by changes in XRD (Figs. 3a-d) for the milling products of cerium dihydride $/ \mathrm{NH}_{3}$ for $7 \mathrm{~h}$, the decomposition started from about $673 \mathrm{~K}$ and the diffraction peaks of cerium nitride CeN with cubic structure were clearly observed upon thermal treatment at about $873 \mathrm{~K}$. This strongly indicates that the reaction of $\mathrm{CeH}_{2.01}$ with $\mathrm{NH}_{3}$ certainly occurs to form amides or amide-like products as a precursor for CeN [19]. It was found that upon treatment at higher temperatures the considerable crystallization of CeN proceeded further. On the other hand, the reaction products of cerium dihydride $/ \mathrm{NH}_{3}$ in an autoclave showed the similar decomposition behavior (Figs. 4a-d), but broad diffraction peaks of CeN were only just observed upon evacuation at around $1073 \mathrm{~K}$. Nanostructured CeN appears to develop from the reaction products by the autoclave method rather than the milling method. This reflects differences in surface areas and crystallite sizes (Table 2); thus, CeN prepared by the autoclave reaction showed surface areas about an order of magnitude larger than CeN by the milling method.

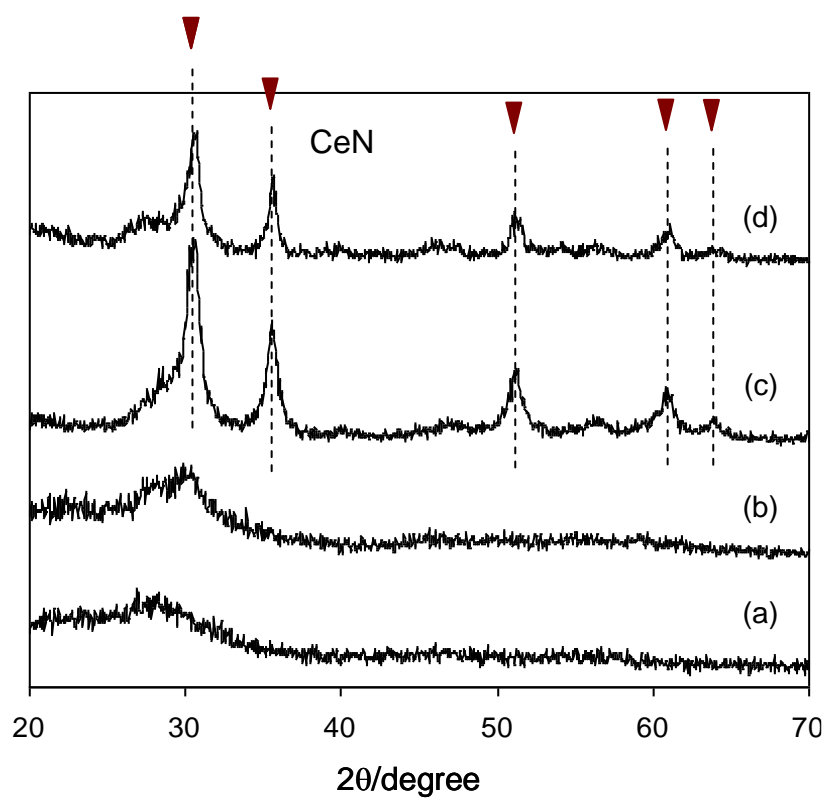

Figure 3. XRD changes with thermal decomposition of the milling products of cerium dihydride/ $\mathrm{NH}_{3}$.

(a) milling products of cerium dihydride $/ \mathrm{NH}_{3}$ for $7 \mathrm{~h}$, (b) decomposition of (a) at $673 \mathrm{~K}$, (c) decomposition of (a) at $873 \mathrm{~K}$ and (d) decomposition of (a) at $1073 \mathrm{~K}$. 


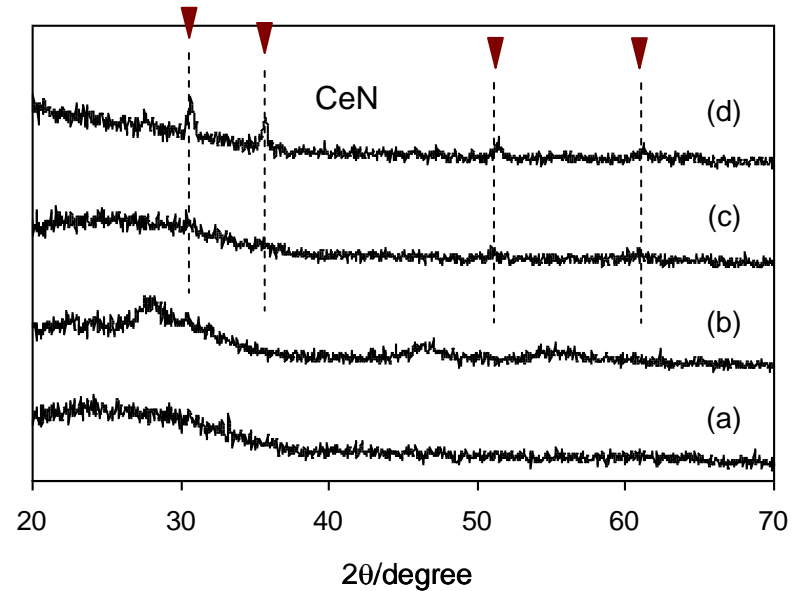

Figure 4. XRD changes with thermal decomposition of the autoclave reaction products of cerium dihydride $/ \mathrm{NH}_{3}$.

(a) reaction products of cerium dihydride $/ \mathrm{NH}_{3}$ at $573 \mathrm{~K}$ for $48 \mathrm{~h}$, (b) decomposition of (a) at $723 \mathrm{~K}$, (c) decomposition of (a) at $873 \mathrm{~K}$ and (d) decomposition of (a) at $1073 \mathrm{~K}$.

When heated above $873 \mathrm{~K}$, the reaction products of RE dihydride (RE: $\mathrm{Pr}, \mathrm{Nd}$ or $\mathrm{Sm}$ ) $/ \mathrm{NH}_{3}$ decomposed to $\mathrm{PrN}$, $\mathrm{NdN}$ or SmN, as well as the case of cerium dihydride $/ \mathrm{NH}_{3}$, respectively (Tables 1 and 2). This similarly leads to speculation of amides or amide-like products in the reaction of the hydrides of praseodymium, neodymium or samarium with ammonia. For gadolinium, terbium dysprosium, holmium and erbium, however, their hydrides exhibited negligible reactivity toward ammonia in reactive ball milling as described above, and naturally, the formation of the nitrides by the thermal decomposition was not confirmed at all. The results obtained were summarized in Table 1.

\subsection{Decomposition processes to nitrides by TDS}

To evaluate the processes of the thermal decomposition to CeN, TDS for the products of cerium dihydride $/ \mathrm{NH}_{3}$ milled for $7 \mathrm{~h}$ was studied. As shown in Fig. 5, the TDS traces showed a desorption peak of $\mathrm{NH}_{3}$ at $350-500 \mathrm{~K}$, broad desorption peaks of $\mathrm{H}_{2}$ at temperatures of around 430 and $500 \mathrm{~K}$, and small desorption of $\mathrm{N}_{2}$ at 700-950 K [19]. Taking into account the conversion processes of ytterbium and europium amides $\left(\mathrm{Yb}\left(\mathrm{NH}_{2}\right)_{2}\right.$ and $\left.\mathrm{Eu}\left(\mathrm{NH}_{2}\right)_{2}\right)$ to the nitrides ( $\mathrm{YbN}$ and $\mathrm{EuN})[10,12]$, respectively, the changes of the cerium amide to the nitride are considered as follows. The cerium amide (Ce( $\left.\mathrm{NH}_{2}\right)_{2}$ ) probably decomposed to form cerium imide (CeNH) with the evolution of $\mathrm{NH}_{3}$ at about $400 \mathrm{~K}$ according to eq. (2). Subsequently, the conversion (eq. 3 ) into the CeN nitride accompanying the evolution of $\mathrm{H}_{2}$ occurred ranging in temperature from 430 to 700 $\mathrm{K}$ as shown in Fig. 5.

Amides are usually considered to be converted into nitrides through imides [22-24]; thus the thermal decomposition of $\mathrm{Ce}\left(\mathrm{NH}_{2}\right)_{2}$ to CeN successively occurs here. However, the formation of $\mathrm{CeNH}$ was not confirmed in XRD (Fig. 3). In the decomposition reactions of RE amides, the formation of imide intermediates hasn't been recognized very often. Juza et al. [22] report that there is no evidence of imide formation in the conversion process of $\mathrm{Eu}\left(\mathrm{NH}_{2}\right)_{2}$ into EuN. However, the TDS results obtained here were almost consistent with the conversion of the cerium amide into the nitride expressed by eqs. (2) and (3). The evolution of $\mathrm{N}_{2}$ observed at $700-950 \mathrm{~K}$ is probably due to further decomposition of $\mathrm{CeN}$ to $\mathrm{CeN}_{1-\mathrm{x}}$.

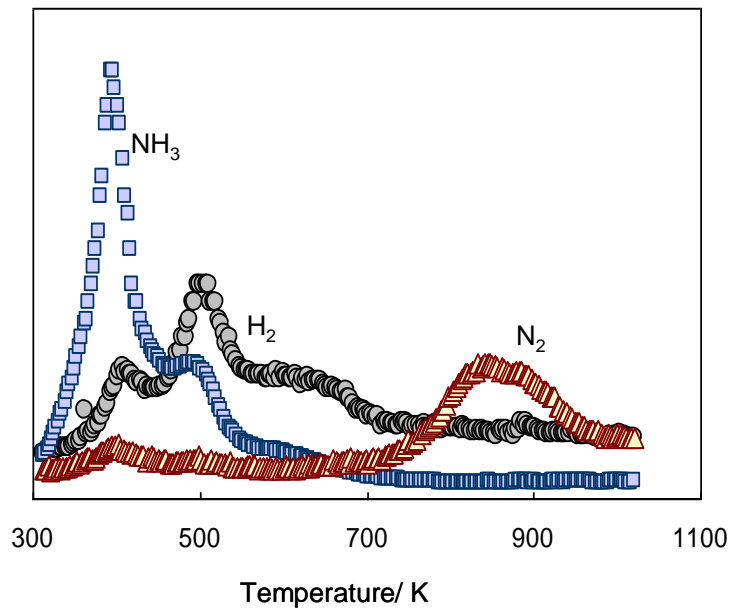

Figure 5. TDS of milling products of cerium dihydride $/ \mathrm{NH}_{3}$ for $7 \mathrm{~h}$.

$\mathrm{Ce}\left(\mathrm{NH}_{2}\right)_{2} \rightarrow \mathrm{CeNH}+\mathrm{NH}_{3}$

$\mathrm{CeNH} \rightarrow \mathrm{CeN}+1 / 2 \mathrm{H}_{2}$

$\mathrm{CeN} \rightarrow \mathrm{CeN}_{1-\mathrm{x}}+\mathrm{x} / 2 \mathrm{~N}_{2}$

The TDS traces of the milling products of RE dihydride (RE: Pr, Nd or Sm)/ $\mathrm{NH}_{3}$ were similar to those of cerium dihydride/ $\mathrm{NH}_{3}$, leading to speculations of consecutive reactions via imide intermediates in the decomposition processes to the nitrides. It is shown by LaValle [18] that the RE nitrides are directly formed when the reaction of hydrides with ammonia is carried out at higher temperatures 1073-1173 K.

TDS of the products obtained by the autoclave reaction of cerium dihydride with ammonia was also measured and the TDS traces obtained were similar to those for the milling products. In conclusion, the 
decomposition reactions of both products proceeded in a similar manner to yield the $\mathrm{CeN}$ nitride. For the autoclave reaction products the desorption of $\mathrm{H}_{2}$ was similarly observed from 500 to $700 \mathrm{~K}$, while the desorption of $\mathrm{N}_{2}$ occurred in somewhat higher temperature range of about 750 to $1000 \mathrm{~K}$. This is consistent with the variations of XRD with thermal treatment as shown in Fig. 4, implying that CeN obtained by the autoclave method exhibits higher heat-stability. CeN obtained by the milling method was chocolate and $0.22 \mathrm{~m}^{2} / \mathrm{g}$, while CeN by the autoclave method was black and $3.9 \mathrm{~m}^{2} / \mathrm{g}$ (Table 2). XRD studies yielded crystallite size estimates for the CeN samples of the milling method and the autoclave method as 5.1 and $2.0 \mathrm{~nm}$, respectively. Moreover, for praseodymium and samarium, the influence of differences between the two preparation methods on the surface areas of the resulting nitrides was also observed as shown in Table 2 . For the RE nitrides examined, the surface areas of the samples obtained by the autoclave method were on the whole larger by over an order of magnitude than those by the milling method. In view of that a marked difference in the decomposition processes to RE nitrides between the reaction products obtained by the two methods was not observed, the drop in surface areas by the ball milling method likely leads to growing over fracturing of nitride particles formed during the milling process.

Table 2. Surface areas and crystallite sizes of RE nitrides obtained by different methods.

\begin{tabular}{|l|l|l|l|l|l|l|}
\hline \multicolumn{2}{|l|}{ CeN } & \multicolumn{2}{l|}{ PrN } & \multicolumn{2}{l|}{ SmN } \\
\hline $\begin{array}{l}\text { Preparation } \\
\text { method }\end{array}$ & $\begin{array}{l}\text { surface } \\
\text { area } / \mathrm{m}^{2} \mathrm{~g}^{-1}\end{array}$ & $\begin{array}{l}\text { crystallite } \\
\text { size } / \mathrm{nm}\end{array}$ & $\begin{array}{l}\text { surface } \\
\text { area } / \mathrm{m}^{2} \mathrm{~g}^{-1}\end{array}$ & $\begin{array}{l}\text { crystallite } \\
\text { size } / \mathrm{nm}\end{array}$ & $\begin{array}{l}\text { surface } \\
\text { area } / \mathrm{m}^{2} \mathrm{~g}^{-1}\end{array}$ & $\begin{array}{l}\text { crystallite } \\
\text { size } / \mathrm{nm}\end{array}$ \\
\hline $\begin{array}{l}\text { Reactive ball } \\
\text { milling }\end{array}$ & 0.22 & 20 & 0.27 & 12 & 0.28 & 18 \\
\hline $\begin{array}{l}\text { Autoclave } \\
\text { reaction }\end{array}$ & 3.9 & 7.9 & 5.3 & 9.5 & 5.9 & 11 \\
\hline
\end{tabular}

\section{Conclusion}

The preparation of nanostructural RE nitrides by the use of the reactions of RE hydrides with ammonia has been studied extensively. CeN, PrN, NdN and SmN were successfully prepared by the thermal decomposition of amides obtained by the reaction of RE dihydride (RE: Ce, Pr, Nd or Sm) with ammonia, whereas GdN, TbN, DyN, HoN and ErN were not obtained in a similar manner due to high stability of the hydrides. The reaction of the RE dihydrides with ammonia was investigated by the two methods: reactive ball milling and autoclave reactions at high pressure. The autoclave reaction method yielded nanostructural nitrides with high surface areas, compared to the ball milling method. XRD and TDS studies strongly suggested that in the decomposition processes of amides to nitrides, the cerium amide decomposed to imide with evolution of ammonia at around $400 \mathrm{~K}$, followed by conversion into the CeN nitride from about $450 \mathrm{~K}$ with evolution of hydrogen.

\section{Acknowledgements}

The financial supports for this research from the Grants-in-Aid for Scientific Research (C) (24561057) are gratefully acknowledged.

\section{References}

[1] S. Roy, A. Chakraborty, and T. K. Maji, "LanthanideOrganic Frameworks for Gas Storage and as Magneto-Luminescent Materials," Chem. Rev., vol. 273-274, pp. 139-164, 2014.

[2] Y. Dwivedi and S.C. Zilio, "Advances in Rare Earth Spectroscopy and Application," J. Nanosci. Nanotech., vol. 14, pp. 1578-1596, 2014.

[3] K. R. Arun, M. Arivanandhan, and Y. Hayakawa, "Recent Advances in Rare Earth-Based Borate Single Crystals: Potential Materials for Nonlinear Optical and Laser Applications," Progress in Crystal Growth and Characterization of Materials, vol. 59, pp. 113-132, 2013.

[4] H. Imamura, "The Metals and Alloys (Prepared Utilizing Liquid Ammonia Solutions) in Catalysis II," in Handbook on the Physics and Chemistry of Rare Earths, K. A. Gschneidner, Jr., L. Eyring (Eds.), vol. 29, pp. 45-74, North-Holland, Amsterdam, 2000.

[5] H. Imamura, Y. Noda, Y. Sakata, and S. Tsuchiya "Catalytic Transfer Hydrogenation of Butene on Hydrogen-absorbing Alloys $\left(\mathrm{LaNi}_{5}, \mathrm{CaNi}_{5}\right.$, $\mathrm{LaNi}_{4} \mathrm{Al}$ )," J. Alloys Compd., vol. 323-324, pp. 601604, 2001. 
[6] H. Imamura, K. Nishimura, K. Sumioki, M. Fujimoto, and Y. Sakata, "Selective Hydrogenation of Benzene to Cyclohexadiene and Cyclohexene by Lanthanide Precipitates Obtained from $\mathrm{Eu}$ or $\mathrm{Yb}$ Metal Solutions in Liquid Ammonia," Chem. Lett, vol. 30, no. 5, pp. 450-451, 2001.

[7] H. Imamura, K. Nishimura, T. Yoshimura, $H$. Yoshimochi, M. Ueno, Y. Sakata, and S. Tsuchiya, "Catalysis of Lanthanides Deposited on Oxide from Eu or Yb Metal Solutions in Liquid Ammonia," J. Mol. Catal. A, vol. 165, pp. 189-197, 2001.

[8] H. Imamura, Y. Maeda, T. Kumai, Y. Sakata, and S. Tsuchiya, "Preparation and Catalytic Properties of Europium and Ytterbium Hydrides Using Liquid Ammonia Solutions of Lanthanide Metals," Catal. Lett., vol. 88, pp. 67-69, 2003.

[9] H. Imamura, T. Nuruyu, T. Kawasaki, T. Teranishi, and Y. Sakata, "Improvement of Selectivity for Partial Hydrogenation of Benzene by Rare Earth Nitride upon $\mathrm{NH}_{3}$ Treatment," Catal. Lett., vol. 96, pp. 185-187, 2004.

[10] H. Imamura, Y. Sakata, T. Nuruyu, and T. Imahashi, "Preparation and Properties of Nanocrystalline Ytterbium and Europium Nitride (YbN and EuN)," J. Alloys Compd., vol. 418, pp. 251-254, 2006.

[11] H. Imamura, T. Kuhara, M. Furutachi., T. Sakamoto, and Y. Sakata, "Selective Dimerization of Ethene over Lanthanide Catalysts Deposited from Eu or Yb Metal Solutions in Liquid Ammonia," Chem. Lett., pp. 744-745, 2002.

[12] H. Imamura, Y. Sakata, Y. Tsuruwaka, and S. Mise, "Preparation and Catalytic Properties of Rare Earth Amides Obtained by Reactions of Eu or $\mathrm{Yb}$ Metals with Liquid Ammonia," J. Alloys Compd., vol. 408-412C, pp. 1113-1117, 2006.

[13] H. Imamura, T. Imahashi, M. Zaimi, and Y. Sakata, "Preparation and Characteristics of Various Rare Earth Nitrides," J. Alloys Compd., vol. 451, no. 1-2, pp. 636-639, 2008.

[14] F. Natalj, B. J. Ruck, N. O. V. Plank, H. J. Trodahl, S. Granville, C. Meyer, and W. R. L. Lambrecht, "RareEarth Mononitrides,” Progress Mat. Sci., vol. 58, pp. 1316-1360, 2013.

[15] B. Kocak, Y. O. Ciftci, K. Cplakoglu, and E. Deligoz, "Structural, Elastic, Electronic, and Thermodynamic Properties of PrN from First Principles Calculations," Physica B, vol. 405, pp. 4139-4144, 2010.

[16] F. Hulliger, "Rare Earth Pnictides," in Handbook on the Physics and Chemistry of Rare Earths, K. A.
Gschneidner, Jr., L. Eyring (Eds.), vol. 4, pp. 153236, North-Holland, Amsterdam, 1979.

[17] H. Y. Leng, T. Ichikawa, S. Hino, N. Hanada, S. Isobe, and H. Fujii, "New Metal-N-H System Composed of $\mathrm{Mg}\left(\mathrm{NH}_{2}\right)_{2}$ and LiH for Hydrogen Storage," J. Phys. Chem. B, vol. 108, pp. 8763-8765, 2004.

[18] D. E. LaValle, "Preparation of Nitrides and Phosphides of Rare-Earth Metals," J. Inorg. Nucl Chem., vol. 24, pp. 930-934, 1962.

[19] H. Imamura, N. Yamada, T. Kanekiyo, K. Ooshima, and Y. Sakata, "Preparation of Cerium Nitride by Reaction of Cerium Hydride with Ammonia," Proc. of the 7th Int. Conf. on $f$ Elements (ICfE-7), Cologne, Germany, 2009, pp. 1-5.

[20] G. G. Libowitz and A. J. Maeland, "Hydrides," in Handbook on the Physics and Chemistry of Rare Earths, K. A. Gschneidner, Jr., L. Eyring (Eds.), vol. 3, pp. 299-336, North-Holland, Amsterdam, 1979.

[21] W. L. Korst and J. C. Warf, "Rare Earth-Hydrogen Systems. I. Structural and Thermodynamic Properties," Inorg. Chem., vol. 5, pp. 1719-1726, 1966.

[22] R. Juza and C. Hadenfeldt, "Preparation and Properties of Europium (II) Amide," Naturwissenschaften, vol. 55, pp. 229, 1968.

[23] S. Salot and J. C. Warf, "Chemical Generation of the Ammoniated Electron via Ytterbium (III)," J. Am. Chem. Soc., vol. 90, pp. 1932-1933, 1968.

[24] K. Howell and L. L. Pytlewski, "The Decomposition Products of Solutions of Europium and Ytterbium Metals in Liquid Ammonia," J. Less-Common Met., vol. 19, pp. 399-404, 1969. 